\title{
Corona deaths in Hamburg, Germany
}

\section{Klaus Püschel ${ }^{1}$ • Jan P. Sperhake ${ }^{1}$}

Published online: 4 June 2020

(C) Springer-Verlag GmbH Germany, part of Springer Nature 2020

In December 2019, the spread of the novel coronavirus SARS-CoV-2 began in Hubei, China, and since then, a worldwide devastating pandemic has developed, which is affecting public and social life to a very high degree and overtaxing the medical systems of many countries.

The first COVID-19 death of a German citizen occurred in Egypt. For a 59-year-old firefighter from Hamburg, the longedfor-holiday trip to Luxor-Assuan-Hurghada turned out to be a deadly mission. The man died on 08 March 2020 in the intensive care unit of a hospital in Hurghada on the Red Sea.

In Hamburg itself, the first case of a corona infection was also registered in March at the University Medical Center Hamburg-Eppendorf. The patient had returned shortly before from a skiing holiday in Austria; since then, the number of infected persons has increased rapidly.

The World Health Organization declared COVID-19 a worldwide medical problem on 30 January and declared the spread of a pandemic on 11 March. In Europe, there have been serious medical consequences in many countries (especially Italy, Spain, France, Great Britain). Most deaths occurred in the USA. No country in the world was spared. A more or less consistent ban on public activities was ordered by the governments.

So far (as of 22 May), almost all registered so-called corona deaths have been documented and evaluated in Hamburg. In a few cases, these were legal autopsies according to $\S 87 \mathrm{StPO}$ (Code of Criminal Procedure); in most cases, the autopsies were ordered by the responsible health authority according to $\S 25$ (4) InfSchG (German Infection Protection Act). From the beginning of the pandemic, we deliberately did not

Klaus Püschel

pueschel@uke.de

Jan P. Sperhake

sperhake@uke.de

1 Department of Legal Medicine, University Medical Center of Hamburg-Eppendorf, Butenfeld 34, 22529 Hamburg, Germany follow the recommendation of the official website of the Robert Koch Institute (RKI - German health monitoring agency) to avoid autopsies.

This recommendation has been made repeatedly in the literature, but it has also been criticised [3, 4]. It is, however, not acceptable for scientific research into this new viral infection with regard to the pathogenesis and clinical course of COVID19. It should be remembered that hygiene and adapted organisational procedures in infectious diseases such as COVID-19 are part of daily routine with regard to protective measures when handling the cadaver and during dissection. The situation is comparable with other infectious cadavers (e.g. influenza, hepatitis, AIDS, EHEC, tuberculosis) - this was underlined by recommendations of the German Society for Forensic Medicine!

The reluctant attitude towards autopsies reminds experienced forensic doctors of the situation at the beginning of the spread of AIDS, when initially only extraordinary autopsies were performed [7]. On the other hand, autopsies have made a significant progress in understanding the disease AIDS, in its spread in special risk groups and with regard to concomitant diseases.

Our own experience with the autopsies performed in Hamburg to date shows very different disease courses and correspondingly diverse morphological and virological findings. Details were presented by Edler et al. [2], Casagrande et al. [1], Puelles et al. [6], and Wichmann et al. [9]. The viral infection of the respiratory tract and the lungs has so far proven to be central to the fatal course of the disease. However, the typical full picture of a viral pneumonia is not always given. In addition, changes are caused by bacterial superinfections or other nosocomial infections, therapy in intensive care units with long-term ventilation, occasional aspiration events, various pre-existing respiratory diseases and concomitant multimorbidity. In particular, we found an unusually high number of ubiquitous thromboses and recurrent pulmonary embolisms (including pulmonary infarctions) - findings with particular relevance for diagnostics and therapy! 
With regard to other organ systems and the virological findings, our results show that SARS-CoV-2 has an organotropism beyond the respiratory tract that affects the heart, kidney, liver and brain [6] and ultimately contributes to the course of COVID-19 disease and the aggravation of pre-existing comorbidities. With special regard to the kidneys, these findings should raise awareness of the clinical management of SARS CoV-2 patients, including routine urine tests, monitoring and treatment of possible protein loss, loss of AT3, thrombophilia and fluid imbalances.

Previous neuropathological findings show non-specific encephalitis, particularly in the brain stem. With a view to cardio-pathological aspects, there is evidence of myocarditis in some cases. The international literature on virological, pathological and clinical aspects of COVID-19 is constantly increasing $[5,8]$.

The prognosis (of some optimistic epidemiologists) is that the rate of fatal courses of the virus infection will flatten out in the near future, at least in some countries. However, it remains to be watched very closely what effects a relaxation of contact bans and other political measures will have, hopefully not a "second wave". The trends in Hamburg (as in the rest of Germany) are promising (see Fig. 1).

The previous age and gender distribution of the deceased shows a predominant proportion of men (approx. 60\%). Overall, the average age is 80 years (range 31-99 years). The average age for men is 78 years (range $31-99$ years) and for women 82 years (range 54-93 years).

All deceased had more or less pronounced relevant previous illnesses (concerning cardiovascular diseases, COPD, neoplasia, metabolic diseases, dementia, others). So far, there are no children or adolescents in our region and very few young adults among the fatalities. Individual cases of children have been reported in other European countries.

So far, we have 1000 unselected deaths with nasopharyngeal swabs in the public mortuary in Hamburg and in the crematorium which led to a relevant number of random discoveries, i.e. COVID-19 cases that would not have been noticed at all in the area of general practitioners, hospitals and public health care and therefore died undetected. This collective will also be carefully further analysed under morphological and epidemiological aspects.

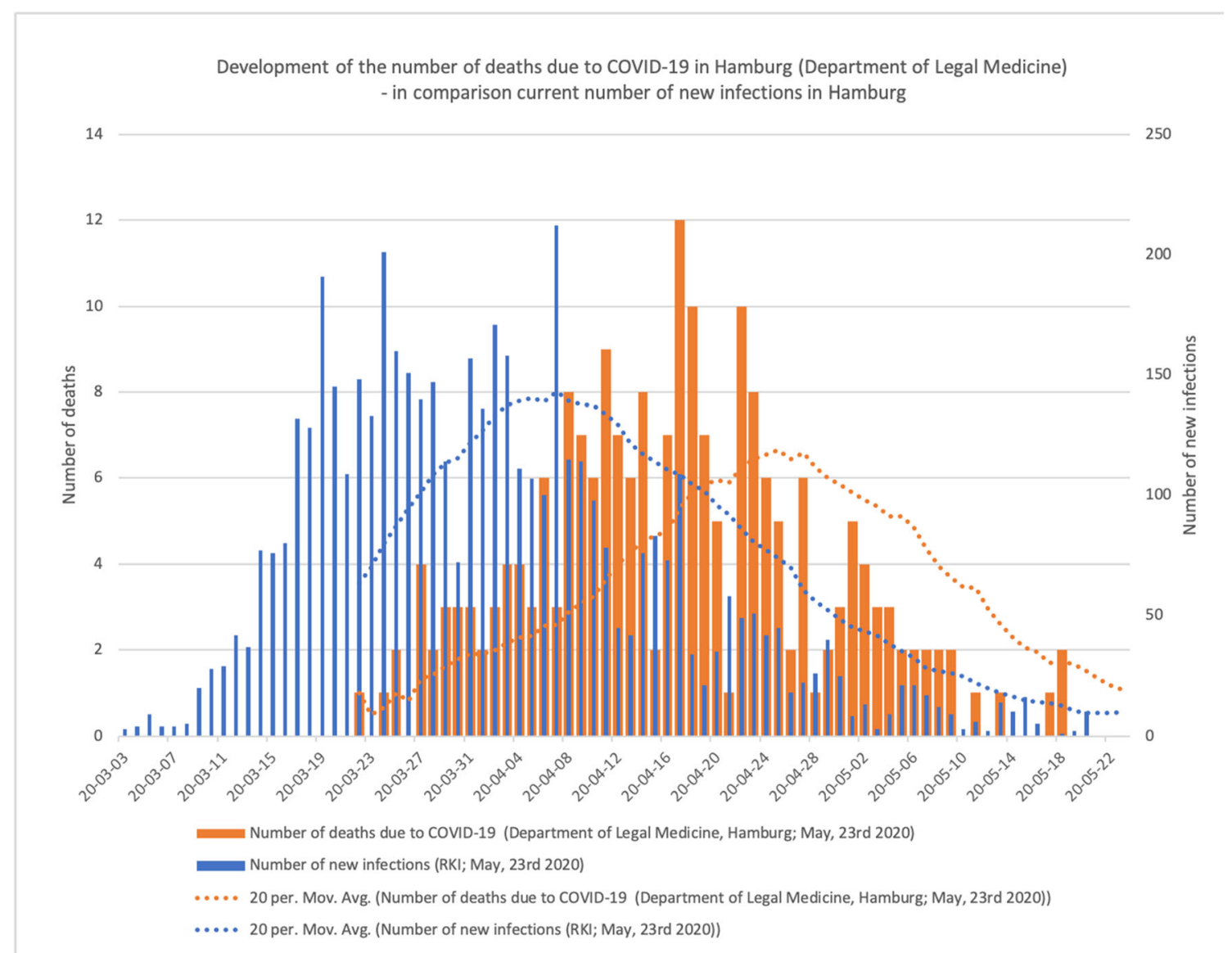

Fig. 1 Statistics of infections and SARS-CoV-2 fatalities in Hamburg/Germany 


\section{Conclusions}

Germany seems to have taken the necessary measures (in particular numerous test examinations, quarantine, restrictions on leaving the country, avoidance of social contacts over a longer period of time) in time to slow down the spread of the virus. The medical care system works very well. So far, there are no bottlenecks anywhere in the treatment of severe COVID-19 diseases in the inpatient sector and especially not in intensive care units. Specific outbreak scenarios (e.g. in nursing homes, in oncology wards, in hospitals in general) have been identified and stopped - the scenario in many other European countries and in other regions of the world is much more serious and threatening.

A careful examination of the dead shows that serious and fatal disease courses can remain manageable in a public health system and in hospitals that are not overloaded. The overwhelming majority of those affected have so far been immunologically or otherwise pre-diseased.

It has been shown that our multidisciplinary investigations of deaths provide accurate data that are not included in a naked summary of the so-called COVID-19 deaths. It is important to inform the population precisely about developments at home and abroad. On the other hand, the press photos of the dead and the presentation of the naked statistical figures can create fear, which is sometimes exaggerated in this virus infection. The careful analysis of the deaths results in convincing approaches for quality assurance and improvement in the field of inpatient therapy as well as many possibilities for systematic research into the spread of the virus and the pathogenesis in the various organs, tissues and cells, all in all the pathology of COVID-19-forensic medicine and pathology can pull together here.

Mortui vivos docent! This is not an empty phrase.

\section{References}

1. Casagrande M, Fitzek A, Püschel K, Aleshcheva, G, Schultheiss HP, Spitzer M, Schultheiss M (2020) First evidence of SARS-CoV-2 in human retina of deceased Covid-19 patients. Ocul Immunol Inflamm, accepted

2. Edler C, Schröder AS, Aepfelbacher M, Fitzek A, Heinemann A, Heinrich F, Klein A, Langenwalder F, Lütgehetmann M, Meißner K, Püschel K, Schädler J, Steurer S, Mushumba H, Sperhake JP (2020) Dying with SARS-CoV-2 infection - an autopsy study of the first consecutive 80 cases in Hamburg, Germany. Int J Legal Med, in this issue

3. Hanley B, Lucas SB, Youd E, Swift B, Osborn M (2020) Autopsy in suspected COVID-19 cases. J Clin Pathol 73(5):239-242

4. Ledford H (2020) Autopsy slowdown hinders quest to determine how coronavirus kills. Nature. https://doi.org/10.1038/d41586-02001355-Z

5. Menter T, Haslbauer JD, Nienhold R, Savic S, Hopfer H, Deigendesch N, Frank S, Turek D, Willi N, Pargger H, Bassetti S, Leuppi JD, Cathomas G, Tolnay M, Mertz KD, Tzankov A (2020) Post-mortem examination of COVID19 patients reveals diffuse alveolar damage with severe capillary congestion and variegated findings of lungs and other organs suggesting vascular dysfunction. Histopathology. https://doi.org/10.1111/his.14134

6. Puelles V, Lütgehetmann M, Lindenmeyer M, Sperhake JP, Wong MN, Allweiss L, Chilla S, Heinemann A, Wanner N, Liu S, Braun F, $\mathrm{Lu}$ S, Pfefferle S, Schröder AS, Edler C, Gross O, Glatzel M, Wichmann D, Wiech T, Kluge S, Püschel K, Aepfelbacher M, Huber T (2020) Multi-organ and renal tropism of SARS-CoV-2. NEJM. https://doi.org/10.1056/NEJMc2011400

7. Püschel K, Tenner-Racz K, Racz P, Dietrich M, Kern P, Schmitz H, Lieske K (1985) AIDS-Todesfälle in Hamburg (Stand: Februar 1985) - Rechtsmedizinische Aspekte. Z Rechtsmed 95:113-121

8. Santurro A, Scopetti M, D'Errico S, Fineschi V (2020) A technical report from the Italian SARS-CoV-2 outbreak. Postmortem sampling and autopsy investigation in cases of suspected or probable COVID19. Forensic Sci Med Pathol. https://doi.org/10.1007/s12024-02000258-9

9. Wichmann D, Sperhake JP, Lütgehetmann M, Steurer S, Edler C, Heinemann A, Heinrich F, Mushumba H, Kniep I, Schröder AS, Burdelski C, de Heer G, Nierhaus A, Frings D, Pfefferle S, Becker H, Bredereke-Wiedling H, de Weerth A, Paschen H-R, SheikzadehEggers S, Stang A, Schmiedel S, Bokemeyer C, Addo M, Aepfelbacher M, Püschel K, Kluge S (2020) Autopsy findings and venous thromboembolism in patients with COVID-19. Ann Intern Med. https://doi.org/10.7326/M20-2003

Publisher's note Springer Nature remains neutral with regard to jurisdictional claims in published maps and institutional affiliations. 